\title{
Plants and Associated Soil Microbiota Cooperatively Suppress Plant-Parasitic Nematodes
}

\author{
Olivera Topalović1t, Muzammil Hussain ${ }^{2 * t}$ and Holger Heuer ${ }^{1 *}$ \\ ${ }^{1}$ Institute for Epidemiology and Pathogen Diagnostics, Julius Kühn-Institut, Federal Research Centre for Cultivated Plants, \\ Braunschweig, Germany, ${ }^{2}$ State Key Laboratory of Mycology, Institute of Microbiology, Chinese Academy of Sciences, \\ Chaoyang, China
}

\section{OPEN ACCESS}

Edited by: Dilantha Fernando,

University of Manitoba, Canada

Reviewed by:

Zafar Ahmad Handoo, Agricultural Research Service (USDA),

United States

Sofia R. Costa,

University of Minho, Portugal

Krzysztof Wieczorek,

University of Natural Resources

and Life Sciences, Vienna, Austria

${ }^{*}$ Correspondence:

Muzammil Hussain

muzammil0991@gmail.com

Holger Heuer

holger.heuer@julius-kuehn.de

tThese authors have contributed equally to this work

Specialty section:

This article was submitted to

Plant Microbe Interactions,

a section of the journal

Frontiers in Microbiology

Received: 14 August 2019

Accepted: 12 February 2020

Published: 28 February 2020

Citation:

Topalović O, Hussain M and Heuer H (2020) Plants and Associated

Soil Microbiota Cooperatively Suppress Plant-Parasitic Nematodes.

Front. Microbiol. 11:313.

doi: 10.3389/fmicb.2020.00313
Disease suppressive soils with specific suppression of soil-borne pathogens and parasites have been long studied and are most often of microbiological origin. As for the plant-parasitic nematodes (PPN), which represent a huge threat to agricultural crops and which successfully defy many conventional control methods, soil progression from conducive to suppressive state is accompanied by the enrichment of specific antagonistic microbial consortia. However, a few microbial groups have come to the fore in diminishing PPN in disease suppressive soils using culture-dependent methods. Studies with cultured strains resulted in understanding the mechanisms by which nematodes are antagonized by microorganisms. Recent culture-independent studies on the microbiome associated with soil, plant roots, and PPN contributed to a better understanding of the functional potential of disease suppressive microbial cohort. Plant root exudation is an important pathway determining host-microbe communication and plays a key role in selection and enrichment of a specific set of microbial antagonists in the rhizosphere as first line of defense against crop pathogens or parasites. Root exudates comprising primary metabolites such as amino acids, sugars, organic acids, and secondary metabolites can also cause modifications in the nematode surface and subsequently affect microbial attachment. A positive interaction between hosts and their beneficial root microbiota is correlated with a low nematode performance on the host. In this review, we first summarized the historical records of nematodesuppressive soils and then focused on more recent studies in this aspect, emphasizing the advances in studying nematode-microbe interactions over time. We highlighted nematode biocontrol mechanisms, especially parasitism, induced systemic resistance, and volatile organic compounds using microbial consortia, or bacterial strains of the genera Pasteuria, Bacillus, Pseudomonas, Rhizobium, Streptomyces, Arthrobacter, and Variovorax, or fungal isolates of Pochonia, Dactylella, Nematophthora, Purpureocillium, Trichoderma, Hirsutella, Arthrobotrys, and Mortierella. We discussed the importance of root exudates in plant communication with PPN and soil microorganisms, emphasizing their role in microbial attachment to the nematode surface and subsequent events of 
nematode parasitism. Comprehensive understanding of the plant-beneficial microbial consortia and the mechanisms underlying disease suppression may help to develop synthetic microbial communities for biocontrol of PPN, thereby reducing nematicides and fertilizers inputs.

Keywords: disease-suppressive soils, plant-parasitic nematodes, root exudates, rhizosphere microbiome, root endophytes, nematode antagonists, induced systemic resistance

\section{INTRODUCTION}

Disease suppressive soils are the conspicuous prototype of a microbe-mediated plant defense against pathogen infection. In general, suppressive soils are those in which soil-borne pathogens and parasites do not establish or persist, establish but cause limited or no disease at all, or establish and cause disease onset initially before it abates (Baker and Cook, 1974; Weller et al., 2002). By contrast, agricultural soils in which pathogens and parasites infect plants and cause diseases are referred to as nonsuppressive or conducive soils (Weller et al., 2002; Garbeva et al., 2004). By definition, general soil suppressiveness, a typical epitome of cumulative soil microbiome competitive activities, is supposed to act against a wide range of soil-borne diseases (Cook and Baker, 1983; Borneman and Becker, 2007). These soils operate on the principle of "seed, feed, and weed" such as it could be initiated by the addition of organic matter in the soil or on the presence of seed and root exudates (seed), which results in the uptake of nutrients by diverse microorganisms (feed), and consequently limiting the outbreak of pathogens and parasites (weed). Therefore, general soil suppressiveness is reduced by soil steaming, but cannot be transferred by small amounts of suppressive soil to conducive soil (Cook and Baker, 1983; Weller et al., 2002). On the other hand, specific soil suppressiveness is typically induced in field soils during crop monoculture after a disease outbreak. It relies on the antagonistic activities of specifically enriched microbial consortia that disrupt the life cycle of plant pathogens or parasites (Raaijmakers and Mazzola, 2016). Specific soil suppressiveness can be eliminated by soil sterilization and biocide treatments and is transferable to a conducive soil with small amounts of a suppressive soil (0.1-10\%) (Yin et al., 2003a; Borneman and Becker, 2007). The criterion of transferability implies that the transferred antagonistic microbes can sufficiently multiply in the conducive soil to reach suppressive densities. This depends on interactions with soil biota, roots, or for specialized antagonists on the density of the pathogen. The distinction between general and specific soil suppressiveness may thus be rather related to the diversity of antagonists than the mechanisms of suppressiveness.

Soils with specific suppressiveness have been reported for plant-parasitic nematodes (PPN) from distinct geographical locations worldwide. Importantly, the life cycle of PPN is distinct from those of pathogenic fungi and bacteria, and diverse microbes were characterized to prey and parasitize different stages of nematodes ( $\mathrm{Li}$ et al., 2015). Consequently, most of the studies were mainly focused on identifying the microbes that can directly kill PPN, while the plant-mediated microbial suppression of nematodes was often overlooked. In soil systems, nematophagous fungi and bacteria have diverse strategies to attack PPN, e.g., nematode-trapping fungi form adhesive hyphal traps, endoparasitic fungi and bacteria use spores, egg- and female-parasitizing fungi use hyphal tips, and several fungi and bacteria produce toxins to prevent plant roots from nematode invasion (Figure 1). Recently, using the nextgeneration technologies several studies have come to the fore signifying the role of soil and root microbiota that disturb the performance of PPN. Thus, a detailed understanding of the microbiome associated with the soil, plant roots, and distinct life stages of PPN may enable us to engineer (synthetic) core microbial consortia that can act as a sustainable alternative to control nematode diseases and to enhance crop productivity. Herein, we will review the studies highlighting the contribution of microbes in inhibiting nematodes in disease suppressive soils using culture-dependent and culture-independent methods. In addition, we will highlight the importance of root-associated microbiota in plant-nematode interactions. Finally, we will tackle some important points on the role of root exudates in nematode infection and their effects on the nematode surface coat (SC), which influence nematode-microbe interactions in soil. This review will give insights into the plant-nematode-microbe interactions in suppressive soils.

\section{HISTORY OF NEMATODE-SUPPRESSIVE SOILS}

The chronological records of nematode-suppressive soils reliably show the progress that has been made in understanding nematode-microbe interactions. The decline of PPN populations in field soils was first reported in 1962 by Collingwood for the cyst nematode Heterodera avenae in the United Kingdom under intensive cropping of cereal hosts (Collingwood, 1962; Kerry, 1982). Since then, suppressive soils have been reported for several nematode species including $H$. avenae in the United Kingdom (Gair et al., 1969; Williams, 1969; Kerry, 1975), Heterodera schachtii in Netherlands, United Kingdom, and United States (Heijbroek, 1983; Crump and Kerry, 1987; Westphal and Becker, 1999), Globodera rostochiensis in Germany (Roessner, 1987), Globodera pallida in the United Kingdom and Germany (Crump and Flynn, 1995; Eberlein et al., 2016), Heterodera glycines in the United States and China (Chen et al., 1996b; Sun and Liu, 2000; Hamid et al., 2017; Hussain et al., 2018), the false root-knot nematode Nacobbus aberrans in Mexico (Zuckerman et al., 1989), root-knot nematodes Meloidogyne spp. in Mexico, United States, Spain, and Germany (Bird and Brisbane, 1988; Zuckerman et al., 1989; Chen et al., 1994b; Pyrowolakis et al., 2002; 
Microbial consortia for biocontrol of plant-parasitic nematodes

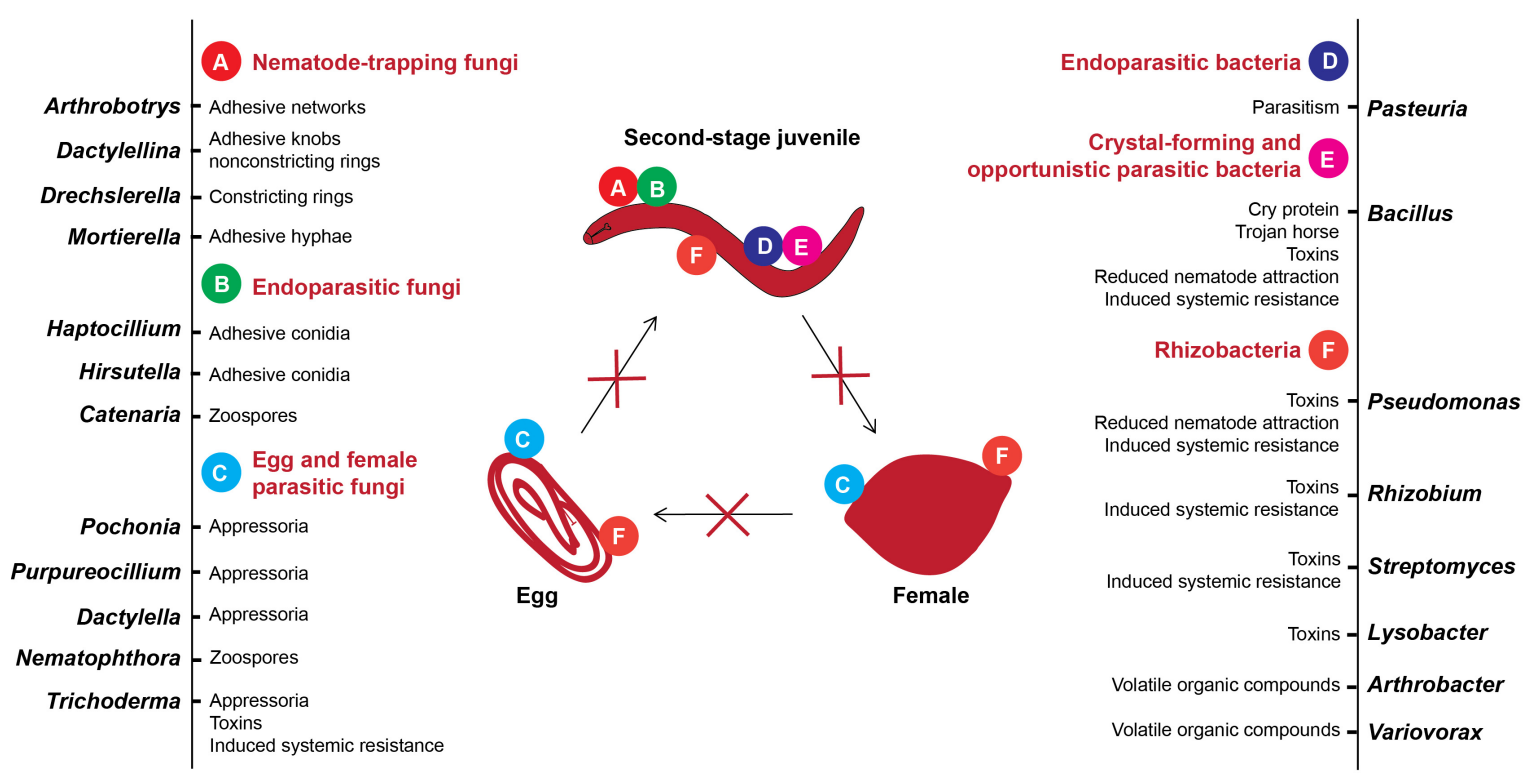

FIGURE 1 | Microbial antagonists of plant-parasitic nematodes and mechanisms of their antagonism.

Bent et al., 2008; Adam et al., 2014b; Giné et al., 2016), and the ring nematode Mesocriconema xenoplax in the United States (Kluepfel et al., 1993, 2002).

General and specific suppression of soil-borne pathogens and parasites is most often of microbiological origin. In 1960s, the formalin application was the only factor known to reduce soil suppressiveness against $H$. avenae in agricultural fields (Williams, 1969). It was suggested that the application of formalin inhibited the parasitic fungi Nematophthora gynophila and Pochonia chlamydosporia and thereby resulted in an increased population density of $H$. avenae (Kerry et al., 1980; Kerry, 1988). Later, several studies demonstrated the microbial involvement in soil suppressiveness by soil autoclaving or heating (Bird and Brisbane, 1988; Zuckerman et al., 1989; Kluepfel et al., 1993; Chen et al., 1996b; Weibelzahl-Fulton et al., 1996; Westphal and Becker, 1999; Sun and Liu, 2000; Bent et al., 2008; Adam et al., 2014b; Eberlein et al., 2016; Giné et al., 2016; Hamid et al., 2017; Bhuiyan et al., 2018), by the application of biocides (Kerry et al., 1980; Crump and Kerry, 1987; Westphal and Becker, 1999; Sun and Liu, 2000; Westphal and Becker, 2001; Pyrowolakis et al., 2002; Yin et al., 2003a,b; Bent et al., 2008; Song et al., 2017), and through soil transplantation (Mankau, 1975; Stirling and Kerry, 1983; Kluepfel et al., 1993; Westphal and Becker, 2000; Sun and Liu, 2000; Yin et al., 2003a,b; Chen, 2007; Bent et al., 2008). Notably, the soil suppressiveness was also observed to be transferred by egg-suspensions of the root-knot nematode Meloidogyne incognita (Orion et al., 2001) and cysts of the sugar beet cyst nematode $H$. schachtii (Westphal and Becker, 2001). Some soils with specific suppressiveness have been characterized and underlying microbial mechanisms were proposed, including parasitism and antibiosis. The role of parasitism in nematodesuppressive soils has extensively been studied for root-knot nematodes (Mankau, 1975), cereal cyst nematodes (Stirling and Kerry, 1983), sugar beet cyst nematodes (Olatinwo et al., 2006b; Becker et al., 2013), and soybean cyst nematodes (Chen, 2007). Antibiosis is an important mechanism of biocontrol, in which the antagonist produces metabolites, such as lytic enzymes, toxins, antibiotics, or volatile compounds, which potentially disrupt the pathogen invasion. Unlike the essential increased initial concentration of parasites for a successful nematode control, it has been noted that nematode suppression by some rhizobacteria, employing different modes of action including antibiosis, can be accomplished at lower microbial densities (Kluepfel et al., 1993). This was the case with ring nematode (M. xenoplax)-suppressive soils, where Pseudomonas sp. producing salicylic acid were found to dramatically alter the development of eggs and to be involved in the inhibition of egg hatch (Kluepfel et al., 2002).

More and more studies on soil microorganisms associated with nematode decline have unraveled an array of new microbial species with an antagonistic potential against PPN. In the following lines we will review bacteria and fungi that were either isolated from the diseased or dead nematodes, or that were identified in nematode-suppressive soils by nextgeneration sequencing. The culture-dependent and cultureindependent approaches in determining nematode antagonists will be compared and discussed.

\section{CULTURE-DEPENDENT STUDIES ON MICROBIOTA IN NEMATODE-SUPPRESSIVE SOILS}

As specific soil suppressiveness is determined by the activity of certain antagonistic microbial species that are main culprits 
for the decrease in nematode population density, the cultivation of such organisms on growth media is an essential step for their large-scale multiplication and prolonged utilization in nematode control. As discussed in the next section, many studies using culture-independent approaches unraveled a high diversity of the microbiome associated with PPN in suppressive soils. However, it has been proposed that only $1 \%$ of microorganisms in nature are cultivable (Amann et al., 1995). This significantly decreases the range of nematode antagonists that can be massproduced. Moreover, cultivation of nematode obligate parasites represents an additional challenge since it often requires the presence of the nematode host. Antagonistic effects of diverse microorganisms were detected in in vitro studies on the biology of free-living nematodes (Huang et al., 2005; Rae et al., 2008), or they appeared as by-products of studies on soil suppressiveness against other pathogens and parasites of plants (Adam et al., 2014a). Nevertheless, there are still numerous microbial species that were isolated from nematodes in suppressive soils (Bird and Brisbane, 1988; Chen et al., 1996a; Weibelzahl-Fulton et al., 1996; Borneman et al., 2004; Borneman and Becker, 2007; Chen, 2007; Adam et al., 2014b; Eberlein et al., 2016; Giné et al., 2013, 2016). In this review we focused on the microorganisms associated with the most important group of PPN, sedentary endoparasites (root-knot and cyst nematodes). We assigned these microbes to two different groups: (1) microbial species associated with suppression of migratory stages of sedentary endoparasitic nematodes and (2) microbial species associated with suppression of sedentary stages of sedentary endoparasitic nematodes.

\section{Microbial Species Associated With Suppression of Migratory Stages of Sedentary Endoparasitic Nematodes}

The most studied microorganism associated with migratory stages of PPN in suppressive soil is the bacterium Pasteuria (Mankau, 1975). The obligate nature of Pasteuria spp. makes them a promising candidate for biocontrol of PPN. Several species of Pasteuria have been reported to parasitize nematodes. Pasteuria penetrans parasitizes Meloidogyne spp. (root-knot nematodes), Pasteuria nishizawae parasitizes Globodera spp. and Heterodera spp. (cyst nematodes), Pasteuria thornei parasitizes Pratylenchus spp. (root-lesion nematodes), and Pasteuria usgae parasitizes Belonolaimus spp., a sting nematodes (Preston et al., 2003; Noel et al., 2005). The attachment of Pasteuria spp. endospores to the nematode cuticle is a first step during parasitism. In case of $P$. penetrans parasitizing Meloidogyne, the spores first attach to the infective second-stage juveniles (J2) in soil, and then, as J2 enter the roots, bacteria produce microcolonies inside the nematode's pseudocelom. Eventually, the development of eggs within females is disrupted (Li et al., 2015). However, in other PPN, endospores can germinate through the cuticle and complete the bacterial life-cycle with new endospores forming in the nematode juvenile (e.g., Pasteuria on H. avenae) (Davies et al., 1990). Pasteuria spp. were repeatedly isolated from soils that exhibited suppressiveness against different nematode species (Stirling and Wachtel, 1980; Stirling and White,
1982; Bird and Brisbane, 1988; Chen et al., 1994b; WeibelzahlFulton et al., 1996; Stirling et al., 2017; Bhuiyan et al., 2018). However, the presence of Pasteuria endospores in soil does not always guarantee nematode parasitism and small numbers of attached spores may not lead to the infection of PPN. For instance, Stirling et al. (2017) have detected Pasteuria spp. in 56\% of the sugarcane fields, but only $5 \%$ of the observed nematodes had attached spores. In one field, Pasteuria sp. was suggested to be responsible for the suppression of Meloidogyne javanica, but only in case when the inoculated $\mathrm{J} 2$ had to cross a distance of more than $4 \mathrm{~cm}$ to reach the roots. The low parasitism rate in some cases appears as a result of a very high nematode-bacterium specificity (Chen and Dickson, 1998). Concentration of bacterial endospores in soil and persistence of antagonism were tested by Bhuiyan et al. (2018). It was shown that reproduction of $M$. javanica was reduced in a concentration-dependent manner, and the level of parasitism was very high with a $96 \%$ decrease in reproduction at 6 months post inoculation, to a $81 \%$ decrease in reproduction at 20 months post inoculation. Amongst other microbial antagonists isolated from suppressive soils that showed high antagonistic effects against PPN, Streptomyces costaricanus was effective against a wide range of nematode species (Dicklow et al., 1993; Esnard et al., 1995). The fungus Hirsutella spp. was demonstrated to produce conidia that adhere to the cuticle of J2 of cyst nematodes, and thereafter penetrate, digest and kill the nematode before root invasion (Stirling and Kerry, 1983; Hussain et al., 2016; Wang et al., 2016a,b). Topalović et al. (2019) have isolated several bacterial genera from the cuticle of the rootknot nematode Meloidogyne hapla in soils with a varying degree of suppressiveness. These were assigned to Microbacterium, Sphingopyxis, Brevundimonas, Acinetobacter, and Micrococcus. Although these are bacteria not obligate parasites of PPN, they showed antagonistic effects against $\mathrm{J} 2$ by increasing mortality, reducing motility, or reducing $\mathrm{J} 2$ invasion into the roots. One of the strains reduced hatching of $\mathrm{J} 2$ from the eggs.

While a direct antagonism of microbes to PPN was mostly regarded as the main mechanism of soil suppressiveness, more recently the plant is understood as a holobiont in association with its microbiome (Hassani et al., 2018). Using split-root systems of tomato plants, Adam et al. (2014a) showed that for Bacillus isolates, although selected as potential biocontrol strains based on their ability to produce nematicidal and fungicidal compounds, the main mechanism suppressing root-knot nematodes was not direct but plant-mediated. Microorganisms do not only target mobile stages of PPN in soil, but can also colonize the roots to parasitize the sedentary stages of endoparasitic nematodes, which is brought up in the following lines.

\section{Microbial Species Associated With Suppression of Sedentary Stages of Endoparasitic Nematodes}

Amongst the first isolated microorganisms that exhibited parasitism against sedentary stages of PPN were the fungi N. gynophila and P. chlamydosporia (former Verticillium chlamydosporium) that lead to the decline of the cyst nematode H. avenae (Kerry, 1982; Stirling and Kerry, 1983). 
P. chlamydosporia is a saprophytic fungus in soil whose association to nematode eggs and cysts in soils is common (Giné et al., 2016; Song et al., 2017; Hu et al., 2018, 2020). Suppression of $H$. schachtii in Californian soil has been extensively studied, and transfers of amounts as small as $0.1 \%$ of this soil to a conducive soil have resulted in a significant decline of nematode reproduction (Westphal and Becker, 2000). Soil suppressiveness was correlated with a high presence of the fungi Dactylella oviparasitica and Fusarium oxysporum in nematode cysts and eggs (Westphal and Becker, 2001). However, involvement of F. oxysporum in nematode suppression is still speculative since in several subsequent studies it failed to cause a nematode decline (Olatinwo et al., 2006a,b; Gao et al., 2008; Becker et al., 2013). In addition, Becker et al. (2013) have pointed out that, although $D$. oviparasitica was highly effective in egg parasitism, viable eggs still remained resistant to this fungus. Since it is also able to parasitize J2, they proposed J2 as a target when applying $D$. oviparasitica as a biocontrol agent against cyst nematodes. Egg parasitism by certain strains of Pseudomonas and Bacillus species isolated from suppressive soils is also important to mention in case of ectoparasitic PPN (Westcott and Kluepfel, 1993; Kluepfel et al., 2002; Colagiero et al., 2017). Kluepfel et al. (2002) have detected several candidate genes in an isolated Pseudomonas strain to be responsible for egg toxicity.

Consortia of other fungi were also isolated from eggs and females of root-knot or cyst nematodes in several studies and for some of them antagonistic effects were confirmed in greenhouse assays (Marban-Mendoza et al., 1992; Chen et al., 1994a, 1996a; Crump and Flynn, 1995). Using microbial strains isolated from diseased nematode stages, different mechanisms to antagonize the nematodes were shown, such as parasitism, production of toxins and traps, or plant-mediated mechanisms. The mass production of antagonists is preceded by their isolation, thus a culture-dependent approach to study nematode-suppressive microbes is of enormous importance. However, microbial identification using DNA-based methods gives a more accurate representation of microbial consortia associated with suppression of PPN, and the following sections cover studies in this aspect.

\section{CULTURE-INDEPENDENT STUDIES ON MICROBIOTA ASSOCIATED WITH PPN IN NEMATODE-SUPPRESSIVE SOILS}

Although several potential microbial antagonists are known to regulate nematode population densities under laboratory and controlled greenhouse conditions, most of them failed to antagonize PPN in the field environment at a distinct geographical location. This inconsistency of microbes to fully express their antagonistic characteristics have been attributed to the lack of their survival within complex microbial communities in soil, or to their inability to better colonize plant roots under different environmental conditions (Alabouvette et al., 2009). Besides, soil suppressiveness is established because of the activity of microbial consortia rather than of just a single species (Costa et al., 2012;
Raaijmakers and Mazzola, 2016). Therefore, several cultivationindependent approaches, including community profiling by oligonucleotide fingerprinting of rRNA genes (OFRG), denaturing gradient gel electrophoresis (DGGE), and highthroughput sequencing of PCR amplified taxonomic marker genes have been employed to decipher microbial cohort contributing to disease suppressiveness within the complex microbial communities, and to infer microbial antagonistic activities operating in nematode-suppressive soils.

\section{Microbes Identified in a Direct Association to PPN}

Several studies have focused on the structure and diversity of microbial communities associated with different life stages of PPN. Since nematode mobile stages reside in soil until they find the suitable roots for feeding, their association with soil microorganisms has been studied the most. A microbial community analysis of root-knot nematode infective J2 revealed a dominance of the bacterial genera Sphingomonas, Micrococcus, Bacillus, Methylobacterium, Rhizobium, and Bosea, and of the fungal genera Davidiella and Rhizophydium in soils that were suppressive against M. hapla (Adam et al., 2014b). Also, J2 of $M$. incognita were enriched by fungi of the genera Malassezia, Plectosphaerella, Gibellulopsis, and Lectera in a soil suppressive against this nematode species (Elhady et al., 2017). Notably, Elhady et al. (2017) also found an association of the bacterium Bacillus thuringiensis and the fungus Plectosphaerella cucumerina with $M$. incognita $\mathrm{J} 2$ in soil. B. thuringiensis produces proteinaceous protoxin crystals (called crystal protein or Cry protein) that cause lysis of the intestine and the nematode's death (Griffitts et al., 2005; Vachon et al., 2012). P. cucumerina was also isolated from the egg masses of $M$. incognita ( $\mathrm{Yu}$ and Coosemans, 1998) and eggs of G. pallida (Kooliyottil et al., 2017), and has been found to infect eggs of G. rostochiensis (Atkins et al., 2003). The microbial community analysis using bacterial $16 \mathrm{~S}$ rRNA gene and ITS amplicon sequencing from G. pallida females showed a dominance of diverse microbiota such as Burkholderia, Bosea, Rhizobium, Devosia, Ralstonia, and Streptomyces, and the fungal genera Davidiella, Hirsutella, Malassezia, Microdochium, Monographella, and Penicillium in potato monoculture soil (Eberlein et al., 2016). Some of the bacterial genera have been previously associated with infective stages of root-knot and lesion nematodes in suppressive soils (Adam et al., 2014b; Elhady et al., 2017).

The adult females of cyst nematodes first appear on the roots and finally develop into mature brown cysts which end up in the surrounding soil. The eggs inside the cysts are colonized by a number of microbes (Nour et al., 2003), and it has been reported that the cysts can transfer suppressive microbes into a nematode-conducive soil (Westphal and Becker, 2001). The earliest effort to characterize bacterial and fungal microbiota inhabiting the cysts in suppressive soil using OFRG identified major taxonomic groups of bacteria ( $\alpha$-Proteobacteria, $\beta$-Proteobacteria, $\gamma$-Proteobacteria, Cytophaga-Flexibacter-Bacteroides, and Actinobacteria) and fungi (D. oviparasitica, F. oxysporum, and Lycoperdon spp.), and 
were then coupled with quantitative PCR to highlight the association of Rhizobium- and D. oviparasitica-like rDNA groups with the suppressiveness against $H$. schachtii (Yin et al., 2003a,b). In addition, using high-throughput amplicon sequencing to examine fungal and bacterial communities from cysts in soil suppressive to $H$. glycines, $\mathrm{Hu}$ et al. (2017) demonstrated that suppressiveness is associated with the change in relative abundance of diverse bacterial and fungal taxa, especially $P$. chlamydosporia, Exophiala spp., and Clonostachys rosea. Similarly, the investigation of fungi from egg masses of $M$. incognita revealed a total of 11 phylotypes, including $P$. chlamydosporia, that were proposed to be involved in regulating root-knot nematode populations (Bent et al., 2008). Recently, Hussain et al. (2018) highlighted the interaction between $H$. glycines cysts and soybean root microbiota using high-throughput sequencing of the V4 region of the bacterial 16S rRNA gene. Specifically, they showed that the microbial consortia enriched upon nematode infection in the rhizosphere and root endosphere also colonized nematode cysts. This points out that cysts are able to serve as an inoculum source for nematode suppressiveness. Moreover, the H. glycines cyst bacterial community was established by the consecutive selection of bacterial taxa from the root endosphere. Bacterial microbiota including, Chitinophaga, Yersinia, Lentzea, Niastella, and Pseudoxanthomonas were dominating the cyst bacterial community in suppressive soil (Hussain et al., 2018). Chitinophaga is a chitin-decomposer with chitinase activity (Sangkhobol and Skerman, 1981; McKee et al., 2019) and the chitin is an essential element of the nematode eggshell (Gortari and Hours, 2008). Chitinases could have an effect on egg viability and hatching (Chen and Peng, 2019). Further, the chitinasegenerated chitooligosaccharides could induce the expression of parasitism-related genes in egg-parasitizing fungi (Escudero et al., 2016) inhabiting the cysts ( $\mathrm{Hu}$ et al., 2018, 2020). Thus, microbiota directly associated with PPN stages in suppressive soils showcasing the ability of nematode suppression elucidate the potential role of diverse microbial consortia in this enticing microbiological milieu.

\section{Microbes Detected in Soils With a Reduced Nematode Performance}

The recent use of cultivation-independent technologies has provided deep insights into the microbial community composition of rhizosphere soils and their contribution in the suppression of PPN. Diverse bacterial and fungal taxa were reported to be enriched in soils with a low presence of PPN or with a poor PPN performance on the host plants grown in these soils. For instance, Giné et al. (2016) investigated the structure of bulk soil microbiota using bacterial and fungal community fingerprinting by DGGE. They found that the bacteria assigned to Lysobacter, Flavobacterium, Chryseobacterium, Flexibacter, Steroidobacter, and Methylobacterium, and the fungi assigned to Cladosporium, Fusarium, Mortierella, Preussia, and Stachybotrys were frequently detected in soils with a low record of root-knot nematodes. Consequently, the fungus $P$. chlamydosporia was isolated and verified to parasitize Meloidogyne eggs (Giné et al., 2016). In another study, $P$. chlamydosporia, together with the fungus Purpureocillium lilacinum and the bacterium Pseudomonas sp., were also marked as major taxa inhabiting the rhizosphere of soybean plants that were grown in soils from north-eastern China, and that were suppressive against $H$. glycines (Hamid et al., 2017). These two egg-parasitic fungi showed a strong geographical preference. The bacterium Pseudomonas sp. had a higher relative abundance in the suppressive than in the conducive soils across all geographical locations (Hamid et al., 2017). It was hypothesized that soils with the ability to suppress specific diseases have a memory of previously encountered pathogens (Raaijmakers and Mazzola, 2016). Those microbial consortia that responded to pathogen attack in a previous plant generation are probably the key drivers of soil memory against specific pathogens (Berendsen et al., 2018). Thus, plants can adopt a "cry for help" strategy during pathogen invasion, leading to the selective enrichment of a specific set of microbes in the soil (Bakker et al., 2018). Furthermore, the high-throughput sequences of the fungal ITS locus showed that both $P$. chlamydosporia and P. lilacinum were increased in the rhizosphere upon combined soil application of the nematode endoparasitic fungus Hirsutella minnesotensis and chitosan to suppress H. glycines (Mwaheb et al., 2017). Similarly, soils with low population densities of Pratylenchus neglectus and Meloidogyne chitwoodi were enriched by the rhizobacteria Arthrobacter, Bacillus, and Lysobacter as revealed by highthroughput sequence analysis of the V4 region of the bacterial $16 S$ rRNA gene (Castillo et al., 2017). With regards to the bacteria, Hussain et al. (2018) using high-throughput sequencing of the V4 region of the bacterial 16S rRNA gene identified less than 30 genera, including Pasteuria, Pseudomonas, and Rhizobium, that were enriched in the rhizosphere and/or root endosphere of soybean grown in suppressive soil, and associated with the suppression of $H$. glycines under a long-term crop monoculture.

Importantly, we summarized the nematode biocontrol mechanisms of the most commonly detected antagonistic microbial consortia from suppressive soils such as the fungi Pochonia, Dactylella, Nematophthora, Purpureocillium, Trichoderma, Hirsutella, Haptocillium, Catenaria, Arthrobotrys, Dactylellina, Drechslerella, and Mortierella, and the bacteria Pasteuria, Bacillus, Pseudomonas, Rhizobium, Streptomyces, Arthrobacter, Lysobacter, and Variovorax (Figure 1). With respect to the fungi, a wide range of the antagonistic species has been described with the ability to trap, parasitize, or intoxicate nematodes, or suppress endoparasitic PPN by inducing systemic resistance in plants (Yang et al., 2007; Szabó et al., 2012; Askary, 2015; Martínez-Medina et al., 2017; Zhang et al., 2019). Likewise, bacterial antagonists often have more than one mode of action. Although the parasitism of nematodes by Pasteuria has been the most extensively studied, the efficiency of nematode antagonism by bacterial toxins, production of volatile organic compounds and nematode repellence from the roots by bacterially induced systemic resistance in plants has also been studied (Siddiqui and Mahmood, 1999; Wei et al., 2003; Sikora et al., 2007; Tian et al., 2007; Li et al., 2015). The results of recent studies 
on characterization of microbiota associated with soil, plant roots, and nematodes in suppressive soils are summarized in Table 1.

To get further insights into the active microbiota and to identify other antagonistic microbial traits involved in nematode-suppressive soils, shotgun metagenomic (Chapelle et al., 2016), metatranscriptomic (Chapelle et al., 2016), and metabolomic (Hayden et al., 2019) approaches might be applied or combined. By combining metagenomics and metatranscriptomics, Chapelle et al. (2016) found that upon fungal invasion the stress-related genes were up-regulated in bacterial families inhabiting the rhizosphere of sugar beet grown in a suppressive soil. The fungal pathogen Rhizoctonia solani secreted phenylacetic and oxalic acid during plant root colonization, leading to oxidative stress in plants and rhizosphere microbes. This oxidative stress response caused a shift in bacterial composition and activated antagonistic traits that confined pathogen infection. Furthermore, Hayden et al. (2019) using metabolomic and metatranscriptomic analyses revealed that sugar molecules were more abundant in the $R$. solani-suppressive than in $R$. solani-conducive soils. They found that the most abundant compound associated with suppressive soils was the antimicrobial secondary metabolite macrocarpal L. These studies demonstrated that the combination of various approaches could provide us with a detailed understanding of the microbes and mechanisms involved in disease-suppressive soils. To acknowledge the enormous plant contribution in nematode antagonism by beneficial microbes in soil, in the next two sections we will focus on nematode-microbe interactions in the rhizosphere and on the involvement of root exudations in this regard.

\section{IMPORTANCE OF THE RHIZOSPHERE MICROBIOTA IN PLANT-NEMATODE INTERACTIONS}

The most intense interactions between the mobile stages of PPN and soil microorganisms occur in the rhizosphere. Nematodes sense environmental signals using different sensilla, but the most studied are paired anterior sensory organs, called amphids. They are positioned in the nematode head region and consist of a glandular sheath cell, a socket cell, and the secretions that are produced by a sheath cell and that surround many dendritic processes (Perry, 1996). Amphids are responsible for navigating PPN to the host roots, providing their positive interaction with the chemical cues released from the roots. Reynolds et al. (2011) proposed that the host range of a certain nematode species determines whether they respond to the general or more specific plant cues. Gene expression in Pratylenchus coffeae was influenced, in a host-specific manner, by cell wall components that were either secreted by the plant or released by degradation of root tissue (Bell et al., 2019). Cellulose or xylan from host plants upregulated the level of $\beta$-1,4-endoglucanase or $\beta$-1,4-endoxylanase genes, respectively. Plants can interfere with PPN signaling (Manohar et al., 2020), and it is likely that also microbial activities modulate and mediate plant-nematode communication. Blocking plant cues or nematode chemoreceptors results in nematode repellence from the roots (Zuckerman, 1983). However, plant root components alone do not entirely affect nematode attractiveness to the roots and a subsequent invasion. In order to reach the roots, nematodes need to travel through a one to several millimeters long soil space in the close vicinity of the root that is called rhizosphere. This is a very active zone along the growing roots with a constant water and nutrient uptake, root exudations and microbial activities (Berg and Smalla, 2009). It was estimated that soil acidity is 10 -fold higher in the rhizosphere than in bulk soil, suggesting very pronounced root effects on chemical and biological characteristics of the surrounding soil (Hübel and Beck, 1993). Both soil type and plant genotype contribute to the composition of the microbial communities in the rhizosphere (Micallef et al., 2009). The composition of exudates varies among plant species (Badri and Vivanco, 2009; Eisenhauer et al., 2016) and genotypes (Mönchgesang et al., 2016). The modulation of the microbiome by root exudates induces a feedback of the microbiome. This plant-soil feedback can support growth and/or health of the plant and of the next plants growing in the same soil (van der Putten et al., 2016; Brinkman et al., 2017). Plantsoil feedback effects varied among plant species, but the number of PPN that fed on the roots of a particular plant species correlated with a negative plant-soil feedback (Wilschut et al., 2019). Plants rely on their root microbiome when they are under attack by pathogens and parasites, leading to a selective enrichment of plant-protective microbes and microbial activities in the rhizosphere (Bakker et al., 2018). The importance of the rhizosphere microbiome in plant-nematode interactions has been extensively reviewed (Kerry, 2000; Griffiths et al., 2007; Sikora et al., 2007; Nyaku et al., 2017; Topalović and Heuer, 2019). Importantly, some recent studies have demonstrated that the transfer of the rhizosphere microbiome from one crop to another significantly alleviated nematode infection and enhanced the plant resistance to PPN (Elhady et al., 2018; Zhou et al., 2019). This effect depended on the plant species. The plant's own microbiome protected it better from root invasion of PPN than the bulk soil microbiome or a foreign microbiome, with the notable exception of the highly suppressive maize microbiome (Elhady et al., 2018). Furthermore, Hussain et al. (2018) revealed that the same subset of microbial OTU was commonly enriched in the rhizosphere and root endosphere upon nematode challenge in suppressive soil. This points out a strong communication between plants and their associated microbiota when under a threat by PPN. In this case, the rhizosphere microbiota can act as a first line of defense against invading PPN, while the root endosphere microbiota can act as a second line of defense against successfully invaded nematodes. Depending on the microorganisms associated with the roots, PPN can be antagonized by parasitism, intoxication, production of volatile organic compounds, or by microbially induced systemic resistance in plants (Figure 2). Most often, the united efforts of more than one mode of action are employed by soil microbiota in nematode suppression. Topalović et al. (2020b) have shown in a split-root experiment that microorganisms from a suppressive soil induced systemic resistance in tomato plants 
TABLE 1 | DNA-based characterization of the bacterial and fungal microbiota inhabiting the soil, plant roots, and nematode stages (mobile and sedentary) in disease suppressive soils.

\begin{tabular}{|c|c|c|c|}
\hline $\begin{array}{l}\text { Nematode } \\
\text { (Reference) }\end{array}$ & Microhabitat & Technique & Microbial genera/species \\
\hline
\end{tabular}

Meloidogyne hapla

(Adam et al.,

2014b)
ITS - DGGE

$16 S-D G G E$

16S - amplicon

incognita

Pratylenchus

penetrans (Elhady

et al., 2017)

Globodera pallida

(Eberlein et al.,

2016)

Heterodera

schachtii (Yin et al.,

2003a,b)

Heterodera glycines

(Song et al., 2017)

Heterodera glycines

(Hu et al., 2017)

Heterodera

glycines (Hussain

et al., 2018)

$16 S$ - DGGE
Meloidogyne

incognita (Bent

et al., 2008)

Meloidogyne spp.

(Giné et al., 2016)

Heterodera glycines

(Hamid et al., 2017)
Infective

stage/bulk soil
Egg masses $\quad$ Fungal - OFRG

Bulk soil

$16 S$ - DGGE

ITS - DGGE

Rhizosphere

ITS - amplicon
16S - amplicon

ITS - amplicon

$16 S$ - amplicon

ITS - amplicon

Bacteria -

OFRG

Fungal - OFRG

ITS - DGGE

ITS - amplicon

$16 S$ - amplicon

16S - amplicon

Cyst
Malassezia, Aspergillus, Cryptococcus, Chaetomium, Eurotium, Ganoderma, Cladosporium, Davidiella, Mortierella, Cylindrocarpon, Rhizophydium

Bradyrhizobium, Sphingomonas, Staphylococcus, Micrococcus, Bacillus, Propionibacterium, Methylobacterium, Streptococcus, Solirubrobacter, Janthinobacterium, Rhizobium, Pedomicrobium, Ochrobactrum, Nitrospira, Devosia, Kaistia, Magnetospirillum, Bosea, Rhodobacter, Pseudomonas

Micrococcus, Rothia, Geobacillus, Streptococcus, Anaerococcus, Peptoniphilus, Clostridium, Mycoplasma, Ochrobactrum, Hirschia, Haematobacter, Paracoccus, Malikia, Janthinobacterium, Neisseria, Vogesella, Shigella, Acinetobacter, Acinetobacter, Enhydrobacter, Pseudomonas

Burkholderia, Fusicatenibacter, Burkholderia, Oscillatoria, Curvibacter, Acinetobacter

Paraburkholderia, Ralstonia, Streptococcus, Staphylococccus, Bacillus thuringiensis, Streptococcus, Acinetobacter, Gemmatimonas, Anaerococcus, Pelomonas, Burkholderia, Neorhizobium

Plectosphaerella, Penicillium, Lectera, Tetracladium, Chaetomium, Petriella, Malassezia, Taphrina, Alternaria, Stemphylium, Cladosporium, Aspergillus, Gibellulopsis Actinophytocola, Aquabacterium, Bosea, Bradyrhizobium, Brevundimonas, Burkholderia, Dermacoccus, Devosia, Moraxella, Pantoea, Pelomonas, Ralstonia, Rhizobium, Rhodobacter, Sphingopyxis, Streptomyces, Zoogloea, Flavobacteria Davidiella, Hirsutella, Malassezia, Microdochium, Monographella, Penicillium, Colletotrichum

Actinobacteria, Cytophaga-Flexibacter-Bacteroides, $\alpha$-Proteobacteria, $\beta$-Proteobacteria, $\gamma$-Proteobacteria, Rhizobium Dactylella oviparasitica, Fusarium oxysporum, Lycoperdon

Geomyces, Aureobasidium, Fusarium, Penicillium, Aspergillus, Cladosporium, Setosphaeria, Alternaria, Mortierella, Cryptococcus, Trichosporon, Galactomyces Trichoderma, Leptosphaeria, Clonostachys, Purpureocillium, Penicillium, Pochonia, Fusarium, Exophiala, Mortierella, Microstroma, Typhula, Phoma, Oudemansiella, Saksenaea, Melanospora, Xylaria, Orbilia, Entoloma

Streptomyces, Enterobacter, Acidovorax, Pseudomonas, Variovorax, Rhizobium, Serratia, Massilia, Dactylosporangium, Lentzea, Amycolatopsis, Mesorhizobium, Actinoplanes, Asteroleplasma, Nocardia, Bradyrhizobium, Actinocorallia, Micromonospora, Streptosporangium, Kribbella, Phyllobacterium, Devosia, Nonomuraea, Actinomadura, Aminobacter, Sphingomonas, Shinella, Chitinophaga, Niastella, Steroidobacter, Kineosporia, Luteolibacter, Lysobacter, Rhodanobacter, Echinococcus

Proteobacteria (Devosia, Ferrovibrio, Sphingopyxis, Phaselicystis, Sphingomonas, Aquabacterium, Steroidobacter, Lysobacter, Albidiferax, Ideonella, Pseudoduganella, Tahibacter, Bosea, Yersinia, Pseudoxanthomonas, Pseudoduganella, Pseudomonas, Steroidobacter), Actinobacteria (Actinophytocola, Actinocorallia, Actinomadura, Nocardia, Planosporangium, Actinoplanes, Promicromonospora, Streptosporangium, Kribbella, Streptomyces, Saccharothrix, Amycolatopsis, Lentzea), Bacteroidetes (Taibaiella, Ohtaekwangia, Dyadobacter, Chitinophaga, Candidatus paenicardinium, Niastella), Chlamydiae (Candidatus rhabdochlamydia), Verrucomicrobia (Verrucomicrobium, Haloferula), Planctomycetes (Planctomyces)

Pochonia, Fusarium, Plectosphaerella, Microdochium, Saccharomyces, Tetracladium, Geomyces, Monacrosporium, Ceratobasidium, Auricularia

Lysobacter, Flavobacterium, Chryseobacterium, Flexibacter, Steroidobacter, Methylobacterium, Candidatus Solibacter

Pseudaleuria, Fusarium, Preussia, Ctenomyces, Mortierella, Cladosporium, Stachybotrys, Pseudallescheria, Psathyrella, Heydenia

Mortierella, Purpureocillium, Fusarium, Pochonia, Clonostachys, Scleroderma, Penicillium, Aspergillus, Corynespora, Guehomyces, Humicola, Eupenicillium, Cryptococcus, Monographella, Tetracladium, Geomyces, Stachybotrys, Ilyonectria, Myrothecium, Monodictys, Arthrobotrys, Dactylellina, Drechslerella, Haptocillium, Hirsutella, Trichoderma, Acremonium, Penicillium, Nematoctonus, Catenaria 
TABLE 1 | Continued

\begin{tabular}{|c|c|c|c|}
\hline $\begin{array}{l}\text { Nematode } \\
\text { (Reference) }\end{array}$ & Microhabitat & Technique & Microbial genera/species \\
\hline & & $16 S$ - amplicon & $\begin{array}{l}\text { Pseudomonas, Massilia, Arthrobacter, Rhizobium, Sphingomonas, Burkholderia, Chitinophaga, } \\
\text { Streptomyces, Mesorhizobium, Novosphingobium, Variovorax, Enterobacter, Bradyrhizobium, } \\
\text { Bacillus, Niastella, Mucilaginibacter }\end{array}$ \\
\hline $\begin{array}{l}\text { Meloidogyne } \\
\text { chitwoodi } \\
\text { Pratylenchus } \\
\text { neglectus (Castillo } \\
\text { et al., 2017) }\end{array}$ & Rhizosphere & 16S - amplicon & $\begin{array}{l}\text { Pasteuria, Brevibacillus, Bacillus, Pseudomonas, Agrobacterium, Arthrobacter, Burkholderia, } \\
\text { Brevundimonas, Clostridium, Corynebacterium, Flavobacterium, Hydrogenophaga, Lysobacter, } \\
\text { Methylobacterium, Mycoplana, Phyllobacterium, Rhizobium, Sphingobacterium, } \\
\text { Stenotrophomonas, Streptomyces, Variovorax }\end{array}$ \\
\hline $\begin{array}{l}\text { Heterodera } \\
\text { glycines (Hussain } \\
\text { et al., 2018) }\end{array}$ & Rhizosphere & 16S - amplicon & $\begin{array}{l}\text { Proteobacteria (Pseudomonas, Ensifer, Shinella, Rhizobium, Aquabacterium), Firmicutes (Pasteuria), } \\
\text { Bacteroidetes (Candidatus paenicardinium), Verrucomicrobia (Haloferula) }\end{array}$ \\
\hline $\begin{array}{l}\text { Heterodera } \\
\text { glycines (Hussain } \\
\text { et al., 2018) }\end{array}$ & $\begin{array}{l}\text { Root } \\
\text { endosphere }\end{array}$ & 16S - amplicon & $\begin{array}{l}\text { Proteobacteria (Phyllobacterium, Aquamicrobium, Rhizobium, Rhodomicrobium, Luteimonas, } \\
\text { Cupriavidus, Bdellovibrio, Devosia, Pseudomonas, Aquabacterium, Hydrogenophaga, Shinella, } \\
\text { Ensifer, Pseudoxanthomonas, Bosea), Actinobacteria (Agromyces, Micromonosporaceae, Lentzea, } \\
\text { Streptomyces, Glycomyces, Microbacteriaceae), Firmicutes (Pasteuria, Fictibacillus), Bacteroidetes } \\
\text { (Candidatus paenicardinium), Planctomycetes (Planctomyces, Rhodopirellula) }\end{array}$ \\
\hline
\end{tabular}

against $M$. hapla, but a combination of a direct antagonism and induced resistance provided a better protection to the plants. They also showed in a sterile system that the microbes attaching to the cuticle of M. hapla in the suppressive soil induced systemic resistance in the plant upon nematode invasion (Topalović et al., 2020a). In addition, in recent years scientists have intensively explored the role of plant and microbial volatile organic compounds on nematode parasitism (Huang et al., 2010; Yang et al., 2012; Barros et al., 2014; Xu et al., 2015; Estupiñan-López et al., 2018; Silva et al., 2018; Pedroso et al., 2019). Thus, the potential of root microbiota to assist plants in fighting PPN is enormous. In the next section, the role of root exudates on nematode-microbe interactions is more comprehensively discussed.

\section{THE ROLE OF THE NEMATODE SURFACE COAT AND ROOT EXUDATES IN PLANT-NEMATODE-MICROBE INTERACTIONS}

When it comes to the interactions with soil microorganisms, the most intriguing feature of the nematode's body is the SC. This is a carbohydrate-rich protein layer secreted over the epicuticle by the hypodermis (Curtis et al., 2011), or by the excretory and nervous system (Lin and McClure, 1996). The SC is probably involved in recognizing the lectin-like protein molecules on the microbial surface by its glycohydrate epitopes (Bird, 2004; Davies and Curtis, 2011). Bird (2004) produced a very concise and detailed review on the recognition and consequences of nematodemicrobe interactions. Depending on the microorganism, the association between the two can result in parasitism, e.g., Anguina sp. and a parasitic Rathayibacter sp. (Bird, 1985; Riley and Reardon, 1995), or Meloidogyne sp. and a parasitic Pasteuria sp. (Davies, 2009), commensalism, e.g., Longidorus sp., Xiphinema sp., Trichodorus sp., and Paratrichodorus sp. as virus vectors (Taylor and Brown, 1997), mutualism, e.g., Steinernema sp. and their endosymbiotic bacteria Xenorhabdus sp. (Lacey and Georgis, 2012), or a phoretic association, e.g., Steinernema and the bacterium Paenibacillus sp. (El-Borai et al., 2005). Some studies have shown that root exudates and some phytohormones, like indole-acetic acid, can alter the SC of PPN (Akhkha et al., 2002; Curtis, 2008) and affect the subsequent attachment of microorganisms to the nematode surface (Singh et al., 2014; Liu et al., 2017). Similarly, López de Mendoza et al. (2000) recorded an increased uptake of the fluorescent lipid analog 5-N-(octadecanoyl) aminofluorescein (AF18) by the SC of J2 of $M$. incognita and the animal parasitic nematode Haemonchus contortus after exposure to tomato root exudates for $30 \mathrm{~min}$. Root exudates from different plant species have a variable effect on attachment of endospores of $P$. penetrans to J2 of root-knot nematodes (Singh et al., 2014; Liu et al., 2017). This suggests that a correlation exists between the host type of root exudates and nematode-microbe interactions in soil. It was found that the attachment of $P$. penetrans endospores to J2 of $M$. incognita was increased when J2 were exposed to the root exudates in the presence of soil microorganisms (Singh et al., 2014). As nematode secretions and the SC components are first perceived by the plant when encountering nematodes (Curtis, 2008; Mendy et al., 2017), masking these nematode receptors upon microbial attachment to the nematode in soil might reduce nematode recognition by the plant. On the other hand, some endoparasitic nematodes, like Meloidogyne spp., hide from the strong plant defense responses by moving through the apoplast until reaching permanent feeding sites (Sijmons et al., 1991; Williamson and Hussey, 1996; Shah et al., 2017). It was recently shown that microorganisms attaching to the J2 of $M$. hapla in suppressive soil before J2 penetration into the roots increase their recognition by the plant by upregulating several PTI-responsive defense genes (Topalović et al., 2020a). Studying the microbially induced chemical and metabolic changes in nematode perception by the plant would better elucidate the exact mechanisms in this tripartite interaction. In 


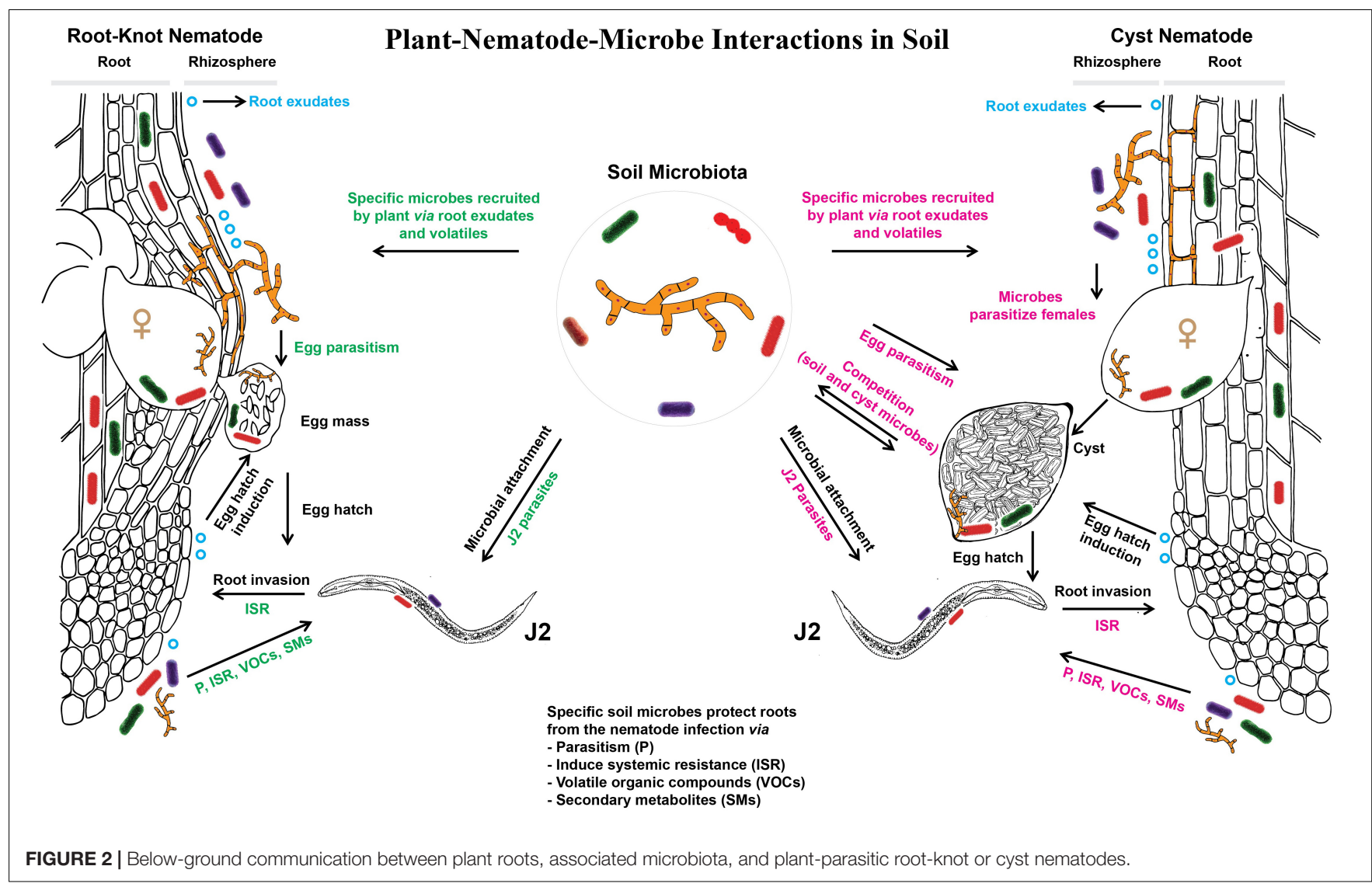

addition, the nematode SC is subjected to a constant turnover and renewal (Spiegel and McClure, 1995; Spiegel et al., 1995; Gravato-Nobre et al., 1999; Curtis et al., 2011). A study with animal parasitic nematodes showed that the SC changed minutes after nematodes are exposed to the conditions equivalent to those inside the host, excluding the influence of molting in such a short time (Proudfoot et al., 1993). The discarded SC deposits inside the plant or animal host can trick plant immune effectors and keep them away from mobile nematodes that are in search for a more stable feeding site (Blaxter et al., 1992). Thus, although the root exudates are important in nematode attraction to the roots, they can also directly affect nematode interactions with soil microorganisms by inducing changes in the surface of PPN. The nature of these interactions and the type of soil microorganisms and root exudates determine whether PPN will evade the plant immune responses or fail to infect the plant.

\section{CONCLUDING REMARKS AND FUTURE PERSPECTIVES}

Plant-parasitic nematodes cause considerable losses to vegetables and agronomic crops worldwide. Notably, most research has been done on a few species of the endoparasitic sedentary genera Meloidogyne, Heterodera, and Globodera. Investigations on other PPN will give the opportunity to generalize conclusions on the interactions of PPN within the phytobiome and to acknowledge species or genus specific differences in life strategies (Topalović et al., 2020b). Microorganisms contributing to the natural suppression of PPN in soils have been studied using culture-dependent and culture-independent methods. Specific suppression of soils is mainly attributed to the antagonistic activities of selective microbial consortia against eggs, juveniles, or females of PPN. The in vitro effects of isolated microbial strains often fail to reproduce upon reintroduction of strains in conducive field soils, due to their inability to colonize roots and fully express putative modes of action. While isolation of specific microbial antagonists is essential for their mass production and application in integrated pest management of PPN, the DNA/RNA-based characterization of the microbiomes associated with plant and nematode is important for a more comprehensive understanding of the interactions between nematodes and their natural enemies in soil, rhizosphere and plant. In parallel, the success of the nematode infection depends on how the signaling molecules from the nematode surface are perceived by the plant roots. Semiochemicals exuded from the plant with root exudates are not only important for the communication between plants and nematodes, but they also directly affect nematode-microbe interactions by modulating components of the nematode surface. Depending on the nematode host range and the microbial composition in soil, endoparasitic nematodes can evade plant defense responses and successfully establish 
inside the roots, or they can be antagonized inside (root endosphere) or outside (rhizosphere) the plant. Thus, plants infinitely rely on their root microbiome during nematode invasion, leading to the enrichment of a specific subset of plant-protective microbes in the rhizosphere and root endosphere (Hussain et al., 2018). Moreover, a thorough understanding of interkingdom microbe-microbe interactions in soil ecosystems may help to enrich the abundance and activities of indigenous keystone microbial taxa by agricultural management practices such as crop rotation (Hu et al., 2018) or tillage (Hu et al., 2017), or through soil amendments like chitin (Cretoiu et al., 2013) or chitosan (Mwaheb et al., 2017). Unraveling the microbiome structure and functions in nematode-suppressive soils and understanding their relationship with the plant will provide us with more knowledge on the mechanisms responsible for

\section{REFERENCES}

Adam, M., Heuer, H., and Hallmann, J. (2014a). Bacterial antagonists of fungal pathogens also control root-knot nematodes by induced systemic resistance of tomato plants. PLoS One 9:e90402. doi: 10.1371/journal.pone.0090402

Adam, M., Westphal, A., Hallmann, J., and Heuer, H. (2014b). Specific microbial attachment to root knot nematodes in suppressive soil. Appl. Environ. Microbiol. 80, 2679-2686. doi: 10.1128/AEM.03905-13

Akhkha, A., Kusel, J., Kennedy, M., and Curtis, R. (2002). Effects of phytohormones on the surfaces of plant-parasitic nematodes. Parasitology 125, 165-175. doi: $10.1017 /$ S0031182002001956

Alabouvette, C., Olivain, C., Migheli, Q., and Steinberg, C. (2009). Microbiological control of soil-borne phytopathogenic fungi with special emphasis on wiltinducing Fusarium oxysporum. New Phytol. 184, 529-544. doi: 10.1111/j. 1469-8137.2009.03014.x

Amann, R., Ludwig, W., and Schleifer, K.-H. (1995). Phylogenetic identification and in situ detection of individual microbial cells without cultivation. Microbiol. Rev. 59, 143-169. doi: 10.1128/mmbr.59.1.143-169.1995

Askary, T. H. (2015). "Nematophagous fungi as biocontrol agents of phytonematodes," in Biocontrol Agents of Phytonematodes, eds T. H. Askary, and P. R. P. Martinelli, (Wallingford: CAB International), 81-125. doi: $10.1079 / 9781780643755.0081$

Atkins, S. D., Clark, I. M., Sosnowska, D., Hirsch, P. R., and Kerry, B. R. (2003). Detection and quantification of Plectosphaerella cucumerina, a potential biological control agent of potato cyst nematodes, by using conventional PCR, real-time PCR, selective media, and baiting. Appl. Environ. Microbiol. 69, 4788-4793. doi: 10.1128/aem.69.8.4788-4793.2003

Badri, D. V., and Vivanco, J. M. (2009). Regulation and function of root exudates. Plant Cell Environ. 32, 666-681. doi: 10.1111/j.1365-3040.2009.01926.x

Baker, K., and Cook, R. J. (1974). Biological Control of Plant Pathogens. New York, NY: WH Freeman and Company, 433.

Bakker, P. A., Pieterse, C. M., de Jonge, R., and Berendsen, R. L. (2018). The soil-borne legacy. Cell 172, 1178-1180. doi: 10.1016/j.cell.2018. 02.024

Barros, A. F., Campos, V. P., da Silva, J. C. P., Pedroso, M. P., Medeiros, F. H. V., Pozza, E. A., et al. (2014). Nematicidal activity of volatile organic compounds emitted by Brassica juncea, Azadirachta indica, Canavalia ensiformis, Mucuna pruriens and Cajanus cajan against Meloidogyne incognita. Appl. Soil Ecol. 80, 34-43. doi: 10.1016/j.apsoil.2014.02.011

Becker, J. S., Borneman, J., and Becker, J. O. (2013). Dactylella oviparasitica parasitism of the sugar beet cyst nematode observed in trixenic culture plates. Biol. Control 64, 51-56. doi: 10.1016/j.biocontrol.2012. 10.007

Bell, C. A., Lilley, C. J., McCarthy, J., Atkinson, H. J., and Urwin, P. E. (2019). Plant-parasitic nematodes respond to root exudate signals with host-specific gene expression patterns. PLoS Pathog. 15:e1007503. doi: 10.1371/journal.ppat. 1007503 nematode suppression, and may help to develop synthetic microbial communities or manage the soil biome for biocontrol of PPN.

\section{AUTHOR CONTRIBUTIONS}

OT and MH conceived, developed the theme, and wrote the manuscript. MH prepared figures. HH contributed to ideas and provided critical revisions of the manuscript.

\section{FUNDING}

OT was funded by the German Research Foundation grant DFG HE6957/1-1.

Bent, E., Loffredo, A., McKenry, M. V., Becker, J. O., and Borneman, J. (2008). Detection and investigation of soil biological activity against Meloidogyne incognita. J. Nematol. 40, 109-118.

Berendsen, R. L., Vismans, G., Yu, K., Song, Y., de Jonge, R., Burgman, W. P., et al. (2018). Disease-induced assemblage of a plant-beneficial bacterial consortium. ISME J. 12, 1496-1507. doi: 10.1038/s41396-018-0093-1

Berg, G., and Smalla, K. (2009). Plant species and soil type cooperatively shape the structure and function of microbial communities in the rhizosphere. FEMS Microbiol. Ecol. 68, 1-13. doi: 10.1111/j.1574-6941.2009.00654.x

Bhuiyan, S. A., Garlick, K., Anderson, J. M., Wickramasinghe, P., and Stirling, G. R. (2018). Biological control of root-knot nematode on sugarcane in soil naturally or artificially infested with Pasteuria penetrans. Australas. Plant Pathol. 47, 45-52. doi: 10.1007/s13313-017-0530-z

Bird, A. F. (1985). The nature of the adhesion of Corynebacterium rathayi to the cuticle of the infective larva of Anguina agrostis. Int. J. Parasitol. 15, 301-308. doi: 10.1016/0020-7519(85)90067-0

Bird, A. F. (2004). "Surface adhesion to nematodes and its consequences," in Nematology: Advances and Perspectives, eds Z. X. Chen, S. Chen, and D. W. Dickson, (Wallingford: CABI Publishing), 295-392.

Bird, A. F., and Brisbane, P. G. (1988). The influence of Pasteuria penetrans in field soils on the reproduction of root-knot nematodes. Revue Nématol. 11, 75-81.

Blaxter, M. L., Page, A. P., Rudin, W., and Maizels, R. M. (1992). Nematode surface coats: actively evading immunity. Parasitol. Today 8, 243-247. doi: 10.1016/ 0169-4758(92)90126-M

Borneman, J., and Becker, J. O. (2007). Identifying microorganisms involved in specific pathogen suppression in soil. Annu. Rev. Phytopathol. 45, 153-172. doi: 10.1146/annurev.phyto.45.062806.094354

Borneman, J., Olatinwo, R., Yin, B., and Becker, J. O. (2004). An experimental approach for identifying microorganisms involved in specified functions: utilisation for understanding a nematode suppressive soil. Australas. Plant Pathol. 33, 151-155.

Brinkman, E. P., Raaijmakers, C. E., de Boer, W., and van der Putten, W. H. (2017). Changing soil legacies to direct restoration of plant communities. AoB Plants 9:1x038. doi: 10.1093/aobpla/plx038

Castillo, J. D., Vivanco, J. M., and Manter, D. K. (2017). Bacterial microbiome and nematode occurrence in different potato agricultural soils. Microb. Ecol. 74, 888-900. doi: 10.1007/s00248-017-0990-2

Chapelle, E., Mendes, R., Bakker, P. A. H., and Raaijmakers, J. M. (2016). Fungal invasion of the rhizosphere microbiome. ISME J. 10, 265-268. doi: 10.1038/ ismej.2015.82

Chen, Q., and Peng, D. (2019). "Nematode Chitin and Application," in: Targeting Chitin-Containing Organisms.Advances in Experimental Medicine and Biology, Vol. 1142. eds Q. Yang, and T. Fukamizo, (Singapore: Springer), 209-219. doi: 10.1007/978-981-13-7318-3_10

Chen, S. (2007). Suppression of Heterodera glycines in soils from fields with longterm soybean monoculture. Biocontrol Sci. Techn. 17, 125-134. doi: 10.1080/ 09583150600937121 
Chen, S., Dickson, D. W., Kimbrough, J. W., McSorley, R., and Mitchell, D. J. (1994a). Fungi associated with females and cysts of Heterodera glycines in a Florida soybean field. J. Nematol. 26, 296-303.

Chen, S. Y., Dickson, D. W., and Mitchell, D. J. (1996a). Pathogenicity of fungi to eggs of Heterodera glycines. J. Nematol. 28, 148-158.

Chen, S. Y., Dickson, D. W., and Mitchell, D. J. (1996b). Population development of Heterodera glycines in response to mycoflora in soil from Florida. Biol. Control 6, 226-231. doi: 10.1006/bcon.1996.0028

Chen, S., Dickson, D. W., and Whitty, E. B. (1994b). Response of Meloidogyne spp. to Pasteuria penetrans, fungi, and cultural practices in tobacco. J. Nematol. 26, 620-625.

Chen, Z. X., and Dickson, D. W. (1998). Review of Pasteuria penetrans: biology, ecology, and biological control potential. J. Nematol. 30, 313-340.

Colagiero, M., Rosso, L. C., and Ciancio, A. (2017). Diversity and biocontrol potential of bacterial consortia associated to root-knot nematodes. Biol. Control 120, 11-16. doi: 10.1016/j.biocontrol.2017.07.010

Collingwood, C. A. (1962). Continuous corn growing and cereal root eelworm in the South-West. NAAS Q. Rev. 58, 70-73.

Cook, R. J., and Baker, K. F. (1983). The Nature and Practice of Biological Control of Plant Pathogens. Saint Paul, MN: American Phytopathological Society, 539.

Costa, S. R., Kerry, B. R., Bardgett, R. D., and Davies, K. G. (2012). Interactions between nematodes and their microbial enemies in coastal sand dunes. Oecologia 170, 1053-1066. doi: 10.1007/s00442-012-2359-z

Cretoiu, M. S., Korthals, G. W., Visser, J. H., and van Elsas, J. D. (2013). Chitin amendment increases soil suppressiveness toward plant pathogens and modulates the actinobacterial and oxalobacteraceal communities in an experimental agricultural field. Appl. Environ. Microbiol. 79, 5291-5301. doi: 10.1128/AEM.01361-13

Crump, D. H., and Flynn, C. A. (1995). Isolation and screening of fungi for the biological control of potato cyst nematodes. Nematologica 41, 628-638. doi: 10.1163/003925995x00567

Crump, D. H., and Kerry, B. R. (1987). Studies on the population dynamics and fungal parasitism of Heterodera schachtii in soil from a sugar-beet monoculture. Crop Prot. 6, 49-55. doi: 10.1016/0261-2194(87)90028-7

Curtis, R. H. C. (2008). Plant-nematode interactions: environmental signals detected by the nematode's chemosensory organs control changes in the surface cuticle and behaviour. Parasite 15, 310-316. doi: 10.1051/parasite/200815 3310

Curtis, R. H. C., Jones, J. T., Davies, K. G., Sharon, E., and Spiegel, Y. (2011). "Plant nematode surfaces," in Biological Control of Plant-Parasitic Nematodes. Building Coherence Between Microbial Ecology and Molecular Mechanisms, eds K. G. Davies, and Y. Spiegel, (Dordrecht: Springer Science + Business Media), 115-144. doi: 10.1007/978-1-4020-9648-8_5

Davies, K. G. (2009). "Understanding the interaction between an obligate hyperparasitic bacterium, Pasteuria penetrans and its obligate plant-parasitic nematode host, Meloidogyne spp," in Natural History of Host-Parasite Interactions. Advances in Parasitology, Vol. 68, ed. J. P. Webster, (Oxford: Academic Press), 211-245. doi: 10.1016/s0065-308x(08)00609-x

Davies, K. G., and Curtis, R. H. C. (2011). Cuticle surface coat of plant-parasitic nematodes. Annu. Rev. Phytopathol. 49, 135-156. doi: 10.1146/annurev-phyto121310-111406

Davies, K. G., Flynn, C. A., Laird, V., and Kerry, B. R. (1990). The life-cycle, population dynamics and host specificity of a parasite of Heterodera avenae, similar to Pasteuria penetrans. Revue Nématol. 13, 303-309.

Dicklow, B. M., Acosta, N., and Zuckerman, B. M. (1993). A novel Streptomyces species for controlling plant-parasitic nematodes. J. Chem. Ecol. 19, 159-173.

Eberlein, C., Heuer, H., Vidal, S., and Westphal, A. (2016). Microbial communities in Globodera pallida females raised in potato monoculture soil. Phytopathology 106, 581-590. doi: 10.1094/Phyto-07-15-0180-R

Eisenhauer, N., Barnes, A. D., Cesarz, S., Craven, D., Ferlian, O., Gottschall, F., et al. (2016). Biodiversity-ecosystem function experiments reveal the mechanisms underlying the consequences of biodiversity change in real world ecosystems. J. Veg. Sci. 27, 1061-1070. doi: 10.1111/jvs.12435

El-Borai, F. E., Duncan, L. W., and Preston, J. F. (2005). Bionomics of a phoretic association between Paenibacillus sp. and the entomopathogenic nematode Steinernema diaprepesi. J. Nematol. 37, 18-25.
Elhady, A., Adss, S., Hallmann, J., and Heuer, H. (2018). Rhizosphere microbiomes modulated by pre-crops assisted plants in defense against plant-parasitic nematodes. Front. Microbiol. 9:1133. doi: 10.3389/fmicb.2018.01133

Elhady, A., Giné, A., Topalovic, O., Jacquiod, S., Sørensen, S. J., Sorribas, F. J., et al. (2017). Microbiomes associated with infective stages of root-knot and lesion nematodes in soil. PLoS One 12:e0177145. doi: 10.1371/journal.pone.0177145

Escudero, N., Ferreira, S. R., Lopez-Moya, F., Naranjo-Ortiz, M. A., MarinOrtiz, A. I., Thornton, C. R., et al. (2016). Chitosan enhances parasitism of Meloidogyne javanica eggs by the nematophagous fungus Pochonia chlamydosporia. Fungal Biol. 120, 572-585. doi: 10.3389/fpls.2017.01415

Esnard, J., Potter, T. I., and Zuckerman, B. M. (1995). Streptomyces costaricanus sp. nov., isolated from nematode suppressive soil. Int. J. Syst. Evol. Microbiol. 45, 775-779. doi: 10.1099/00207713-45-4-775

Estupiñan-López, L., Campos, V. P., da Silva Júnior, J. C., Pedroso, M. P., Terra, W. C., and da Silva, J. C. P. (2018). Volatile compounds produced by Fusarium spp. isolated from Meloidogyne paranaensis egg masses and corticous root tissues from coffee crops are toxic to Meloidogyne incognita. Trop. Plant Pathol. 43, 183-193. doi: 10.1007/s40858-017-0202-0

Gair, R., Mathias, P. L., and Harvey, P. N. (1969). Studies of cereal nematode populations and cereal yields under continuous or intensive culture. Ann. Appl. Biol. 63, 503-512. doi: 10.1111/j.1744-7348.1969.tb02846.x

Gao, X., Yin, B., Borneman, J., and Becker, J. O. (2008). Assessment of parasitic activity of Fusarium strains obtained from a Heterodera schachtii-suppressive soil. J. Nematol. 40, 1-6.

Garbeva, P., van Veen, J. A., and van Elsas, J. D. (2004). Microbial diversity in soil: selection microbial populations by plant and soil type and implications for disease suppressiveness. Annu. Rev. Phytopathol. 42, 243-270. doi: 10.1146/ annurev.phyto.42.012604.135455

Giné, A., Bonmatí, M., Sarro, A., Stchiegel, A., Valero, J., Ornat, C., et al. (2013). Natural occurrence of fungal egg parasites of root-knot nematodes, Meloidogyne spp. in organic and integrated vegetable production systems in Spain. Biocontrol 58, 407-416. doi: 10.1007/s10526-012-9495-6

Giné, A., Carrasquilla, M., Martínez-Alonso, M., Gaju, N., and Sorribas, F. J. (2016). Characterization of soil suppressiveness to root-knot nematodes in organic horticulture in plastic greenhouse. Front. Plant Sci. 7:164. doi: 10.3389/fpls. 2016.00164

Gortari, M. C., and Hours, R. A. (2008). Fungal chitinases and their biological role in the antagonism onto nematode eggs: a review. Mycol. Prog. 7, 221-238. doi: 10.1007/s11557-008-0571-3

Gravato-Nobre, M. J., McClure, M. A., Dolan, L., Calder, G., Davies, K. G., Mulligan, B., et al. (1999). Meloidogyne incognita surface antigen epitopes in infected Arabidopsis roots. J. Nematol. 31, 212-223.

Griffiths, B. S., Christensen, S., and Bonkowski, M. (2007). "Microfaunal interactions in the rhizosphere, how nematodes and protozoa link above- and belowground processes," in The Rhizosphere. An Ecological Perspective, eds Z. G. Cardon, and J. L. Whitbeck, (Amsterdam: Elsevier Academic Press), 57-71. doi: 10.1016/b978-012088775-0/50005-7

Griffitts, J. S., Haslam, S. M., Yang, T., Garczynski, S. F., Mulloy, B., Morris, H., et al. (2005). Glycolipids as receptors for Bacillus thuringiensis crystal toxin. Science 307, 922-925. doi: 10.1126/science.1104444

Hamid, M. I., Hussain, M., Wu, Y., Zhang, X., Xiang, M., and Liu, X. (2017). Successive soybean-monoculture cropping assembles rhizosphere microbial communities for the soil suppression of soybean cyst nematode. FEMS Microbiol. Ecol. 93:fiw222. doi: 10.1093/femsec/fiw222

Hassani, M. A., Durán, P., and Hacquard, S. (2018). Microbial interactions within the plant holobiont. Microbiome 6:58. doi: 10.1186/s40168-018-0445-0

Hayden, H. L., Rochfort, S. J., Ezernieks, V., Savin, K. W., and Mele, P. M. (2019). Metabolomics approaches for the discrimination of disease suppressive soils for Rhizoctonia solani AG8 in cereal crops using 1H NMR and LC-MS. Sci. Total Environ. 651, 1627-1638. doi: 10.1016/j.scitotenv.2018.09.249

Heijbroek, W. (1983). Some effects of fungal parasites on the population development of the beet cyst nematode (Heterodera schachtii Schm.). Meded. Fac. Landbouwwet. Rijksuniv. Gent 48, 433-439.

Hu, J., Hussain, M., Zhang, X., Tian, J., Liu, X., Duan, Y., et al. (2020). Abundant and diverse fungal microbiota inhabit the white females and brown cysts of the cereal cyst nematode. Appl. Soil Ecol. 147:103372. doi: 10.1016/j.apsoil.2019. 103372 
Hu, W., Samac, D. A., Liu, X., and Chen, S. (2017). Microbial communities in the cysts of soybean cyst nematode affected by tillage and biocide in a suppressive soil. Appl. Soil Ecol. 119, 396-406. doi: 10.1016/j.apsoil.2017.07.018

Hu, W., Strom, N., Rajendran, D., Chen, S., Bushley, K., and Haarith, D. (2018). Mycobiome of cysts of the soybean cyst nematode under long term crop rotation. Front. Microbiol. 9:386. doi: 10.3389/fmicb.2018.00386

Huang, X., Tian, B., Niu, Q., Yang, J., Zhang, L., and Zhang, K. (2005). An extracellular protease from Brevibacillus laterosporus G4 without parasporal crystals can serve as a pathogenic factor in infection of nematodes. Res. Microbiol. 156, 719-727. doi: 10.1016/j.resmic.2005.02.006

Huang, Y., Xu, C. K., Ma, L., Zhang, K., Duan, C. Q., and Mo, M. H. (2010). Characterisation of volatiles produced from Bacillus megaterium YFM3.25 and their nematicidal activity against Meloidogyne incognita. Eur. J. Plant Pathol. 126, 417-422. doi: 10.1007/s10658-009-9550-z

Hübel, F., and Beck, E. (1993). In-situ determination of the P-relations around the primary root of maize with respect to inorganic and phytate-P. Plant Soil 157, 1-9. doi: 10.1007/BF02390221

Hussain, M., Hamid, M. I., Tian, J., Hu, J., Zhang, X., Chen, J., et al. (2018). Bacterial community assemblages in the rhizosphere soil, root endosphere and cyst of soybean cyst nematode-suppressive soil challenged with nematodes. FEMS Microbiol. Ecol. 94:fiy142. doi: 10.1093/femsec/fiyl42

Hussain, M., Hamid, M. I., Wang, N., Bin, L., Xiang, M., and Liu, X. (2016). The transcription factor SKN7 regulates conidiation, thermotolerance, apoptoticlike cell death and parasitism in the nematode endoparasitic fungus Hirsutella minnesotensis. Sci. Rep. 6:30047. doi: 10.1038/srep30047

Kerry, B. (1988). Fungal parasites of cyst nematodes. Agric. Ecosyst. Environ. 24, 293-305. doi: 10.1016/0167-8809(88)90073-4

Kerry, B. R. (1975). Fungi and the decrease of cereal cyst-nematode populations in cereal monoculture. EPPO Bull. 5, 353-361. doi: 10.1111/j.1365-2338.1975. tb02485.x

Kerry, B. R. (1982). The decline of Heterodera avenae populations. EPPO Bull. 12, 491-496. doi: 10.1111/j.1365-2338.1982.tb01834.x

Kerry, B. R. (2000). Rhizosphere interactions and the exploitation of microbial agents for the biological control of plant-parasitic nematodes. Annu. Rev. Phytopathol. 38, 423-441. doi: 10.1146/annurev.phyto.38.1.423

Kerry, B. R., Crump, D. H., and Mullen, L. A. (1980). Parasitic fungi, soil moisture, and multiplication of the cereal cyst nematode. Heterodera avenae. Nematologica 26, 57-68. doi: 10.1163/187529280x00567

Kluepfel, D. A., McInnis, T. M., and Zehr, E. I. (1993). Involvement of rootcolonizing bacteria in peach orchard soils suppressive of the nematode Criconemella xenoplax. Phytopathology 83, 1240-1245.

Kluepfel, D. A., Nyczepir, A. P., Lawrence, J. E., Wechter, W. P., and Leverentz, B. (2002). Biological control of the phytoparasitic nematode Mesocriconema xenoplax on peach trees. J. Nematol. 34, 120-123.

Kooliyottil, R., Dandurand, L.-M., and Knudsen, G. R. (2017). Prospecting fungal parasites of the potato cyst nematode Globodera pallida using a rapid screening technique. J. Basic Microbiol. 57, 386-392. doi: 10.1002/jobm.201600683

Lacey, L. A., and Georgis, R. (2012). Entomopathogenic nematodes for control of insect pests above and below ground with comments on commercial production. J. Nematol. 44, 218-225.

Li, J., Zou, C., Xu, J., Ji, X., Niu, X., Yang, J., et al. (2015). Molecular mechanisms of nematode-nematophagous microbe interactions: basis for biological control of plant-parasitic nematodes. Annu. Rev. Phytopathol. 53, 67-95. doi: 10.1146/ annurev-phyto-080614-120336

Lin, H. J., and McClure, M. A. (1996). Surface coat of Meloidogyne incognita. J. Nematol. 28, 216-224.

Liu, C., Timper, P., Ji, P., Mekete, T., and Joseph, S. (2017). Influence of root exudates and soil on attachment of Pasteuria penetrans to Meloidogyne arenaria. J. Nematol. 49, 304-310. doi: 10.21307/jofnem-2017-076

López de Mendoza, M. E., Modha, J., Roberts, M. C., Curtis, R. H. C., and Kusel, J. R. (2000). Changes in the lipophilicity of the surfaces of Meloidogyne incognita and Haemonchus contortus during exposure to host signals. Parasitology 120, 203-209. doi: 10.1017/S0031182099005326

Mankau, R. (1975). Bacillus penetrans n. comb. causing a virulent disease of plantparasitic nematodes. J. Invertebr. Pathol. 26, 333-339. doi: 10.1016/00222011(75)90231- 1

Manohar, M., Tenjo-Castano, F., Chen, S., Zhang, Y. K., Kumari, A., and Williamson, V. M. (2020). Plant metabolism of nematode pheromones mediates plant-nematode interactions. Nat. Commun. 11:208. doi: 10.1038/s41467-01914104-2

Marban-Mendoza, N., Garcia, E. R., Dicklow, B. M., and Zuckerman, B. M. (1992). Studies on Paecilomyces marquandii from nematode suppressive chinampa soils. J. Chem. Ecol. 18, 775-783. doi: 10.1007/bf00994614

Martínez-Medina, A., Fernández, I., Lok, G. B., Pozo, M. J., Pieterse, C. M. J., and Van Wees, S. C. M. (2017). Shifting from priming of salicylic acid- to jasmonic acid-regulated defences by Trichoderma protects tomato against the root knot nematode Meloidogyne incognita. New Phytol. 213, 1363-1377. doi: 10.1111/nph.14251

McKee, L. S., Martínez-Abad, A., Ruthes, A. C., Vilaplana, F., and Brumer, H. (2019). Focused metabolism of $\beta$-glucans by the soil bacteroidetes species Chitinophaga pinensis. Appl. Environ. Microbiol. 85:e02231-18. doi: 10.1128/ AEM.02231-18

Mendy, B., Wang'ombe, M. W., Radakovic, Z. S., Holbein, J., Ilyas, M., Chopra, D., et al. (2017). Arabidopsis leucine-rich repeat receptor-like kinase NILR1 is required for induction of innate immunity to parasitic nematodes. PLoS Pathog. 13:e1006284. doi: 10.1371/journal.ppat.1006284

Micallef, S. A., Channer, S., Shiaris, M. P., and Colón-Carmona, A. (2009). Plant age and genotype impact the progression of bacterial community succession in the Arabidopsis rhizosphere. Plant Signal. Behav. 4, 777-780. doi: 10.4161/psb. 4.8.9229

Mönchgesang, S., Strehmel, N., Schmidt, S., Westphal, L., Taruttis, F., Müller, E., et al. (2016). Natural variation of root exudates in Arabidopsis thaliana-linking metabolomic and genomic data. Sci. Rep. 6:29033. doi: 10.1038/srep29033

Mwaheb, M. A., Hussain, M., Tian, J., Zhang, X., Hamid, M. I., El-Kassim, N. A., et al. (2017). Synergetic suppression of soybean cyst nematodes by chitosan and Hirsutella minnesotensis via the assembly of the soybean rhizosphere microbial communities. Biol. Control 115, 85-94. doi: 10.1016/j.biocontrol.2017.09.011

Noel, G. R., Atibalentja, N., and Domier, L. L. (2005). Emended description of Pasteuria nishizawae. Int. J. Syst. Evol. Microbiol. 55, 1681-1685. doi: 10.1099/ ijs.0.63174-0

Nour, S. M., Lawrence, J. R., Zhu, H., Swerhone, G. D., Welsh, M., Welacky, T. W., et al. (2003). Bacteria associated with cysts of the soybean cyst nematode (Heterodera glycines). Appl. Environ. Microbiol. 69, 607-615. doi: 10.1128/AEM. 69.1.607-615.2003

Nyaku, S. T., Affokpon, A., Danquah, A., and Brentu, F. C. (2017). "Harnessing useful rhizosphere microorganisms for nematode control," in Nematology Concepts, Diagnosis and Control, eds M. M. Shah, and M. Mahamood, (London: InTech), 153-182.

Olatinwo, R., Becker, J. O., and Borneman, J. (2006a). Suppression of Heterodera schachtii populations by Dactylella oviparasitica in four soils. J. Nematol. 38 , 345-348.

Olatinwo, R., Yin, B., Becker, J. O., and Borneman, J. (2006b). Suppression of the plant-parasitic nematode Heterodera schachtii by the fungus Dactylella oviparasitica. Phytopathology 96, 111-114. doi: 10.1094/Phyto-96-0111

Orion, D., Kritzman, G., Meyer, S. L., Erbe, E. F., and Chitwood, D. J. (2001). A role of the gelatinous matrix in the resistance of root-knot nematode (Meloidogyne spp.) eggs to microorganisms. J. Nematol. 33, 203-207.

Pedroso, L. A., Campos, V. P., Pedroso, M. P., Barros, A. F., Freire, E. S., and Resende, F. M. (2019). Volatile organic compounds produced by castor bean cake incorporated into the soil exhibit toxic activity against Meloidogyne incognita. Pest Manag. Sci. 75, 476-483. doi: 10.1002/ps.5142

Perry, R. N. (1996). Chemoreception in plant parasitic nematodes. Annu. Rev. Phytopathol. 34, 181-199. doi: 10.1146/annurev.phyto.34.1.181

Preston, J. F., Dickson, D. W., Maruniak, J. E., Nong, G., Brito, J. A., Schmidt, L. M., et al. (2003). Pasteuria spp.: systematics and phylogeny of these bacterial parasites of phytopathogenic nematodes. J. Nematol. 35, 198-207.

Proudfoot, L., Kusel, J. R., Smith, H. V., Harnett, W., Worms, M. J., and Kennedy, M. W. (1993). Rapid changes in the surface of parasitic nematodes during transition from pre- to post-parasitic forms. Parasitology 107, 107-117. doi: $10.1017 /$ s0031182000079464

Pyrowolakis, A., Westphal, A., Sikora, R. A., and Becker, J. O. (2002). Identification of root-knot nematode suppressive soils. Appl. Soil Ecol. 19, 51-56. doi: 10.1016/ S0929-1393(01)00170-6

Raaijmakers, J. M., and Mazzola, M. (2016). Soil immune responses. Science 352, 1392-1393. doi: $10.1126 /$ science.aaf3252 
Rae, R., Riebesell, M., Dinkelacker, I., Wang, Q., Herrmann, M., Weller Andreas, M., et al. (2008). Isolation of naturally associated bacteria of necromenic Pristionchus nematodes and fitness consequences. J. Exp. Biol. 211, 1927-1936. doi: $10.1242 /$ jeb.014944

Reynolds, A. M., Dutta, T. K., Curtis, R. H. C., Powers, S. J., Gaur, H. S., and Kerry, B. R. (2011). Chemotaxis can take plant-parasitic nematodes to the source of a chemo-attractant via the shortest possible routes. J. R. Soc. Interface 8, 568-577. doi: 10.1098/rsif.2010.0417

Riley, I. T., and Reardon, T. B. (1995). Isolation and characterization of Clavibacter tritici associated with Anguina tritici in wheat from Western Australia. Plant Pathol. 44, 805-810. doi: 10.1111/j.1365-3059.1995.tb02739.x

Roessner, J. (1987). Pilze als antagonisten von Globodera rostochiensis. Nematologica 33, 106-118. doi: 10.1163/187529287x00254

Sangkhobol, V., and Skerman, V. B. D. (1981). Chitinophaga, a new genus of chitinolytic myxobacteria. Int. J. Syst. Bacteriol. 31, 285-293. doi: 10.1099/ 00207713-31-3-285

Shah, S. J., Anjam, M. S., Mendy, B., Anwer, M. A., Habash, S. S., Lozano-Torres, J. L., et al. (2017). Damage-associated responses of the host contribute to defence against cyst nematodes but not root-knot nematodes. J. Exp. Bot. 68, 5949-5960. doi: 10.1093/jxb/erx374

Siddiqui, Z. A., and Mahmood, I. (1999). Role of bacteria in the management of plant-parasitic nematodes: a review. Bioresour. Technol. 69, 167-179. doi: 10.1016/S0960-8524(98)00122-9

Sijmons, P. C., Grundler, F. M. W., von Mende, N., Burrows, P. R., and Wyss, U. (1991). Arabidopsis thaliana as a new model host for plantparasitic nematodes. Plant J. 1, 245-254. doi: 10.1111/j.1365-313X.1991.00 245. $\mathrm{x}$

Sikora, R. A., Schäfer, K., and Dababat, A. A. (2007). Modes of action associated with microbially induced in planta suppression of plant-parasitic nematodes. Australas. Plant Pathol. 36, 124-134. doi: 10.1071/AP07008

Silva, J. C. P., Campos, V. P., Barros, A. F., Pedroso, M. P., Terra, W. C., Lopez, L. E., et al. (2018). Plant volatiles reduce the viability of the root-knot nematode Meloidogyne incognita either directly or when retained in water. Plant Dis. 102, 2170-2179. doi: 10.1094/PDIS-01-18-0143-RE

Singh, J., Kumar, M. U., and Walia, R. K. (2014). Influence of plant root exudates on the adherence of Pasteuria penetrans endospores. Nematology 16, 121-124. doi: 10.1163/15685411-00002768

Song, J., Li, S., Wei, W., Xu, Y., and Yao, Q. (2017). Assessment of parasitic fungi for reducing soybean cyst nematode with suppressive soil in soybean fields of northeast China. Acta Agric. Scand. B Soil Plant Sci. 67, 730-736. doi: 10.1080/09064710.2017.1343377

Spiegel, Y., Inbar, J., Kahane, I., and Sharon, E. (1995). Carbohydrate-recognition domains on the surface of phytophagous nematodes. Exp. Parasitol. 80, 220227. doi: 10.1006/expr.1995.1027

Spiegel, Y., and McClure, M. A. (1995). The surface coat of plant-parasitic nematodes: chemical composition, origin, and biological role - a review. J. Nematol. 27, 127-134.

Stirling, G. R., and Kerry, B. R. (1983). Antagonists of the cereal cyst nematode Heterodera avenae Woll. in Australian soils. Aust. J. Exp. Agr. 23, 318-324.

Stirling, G. R., and Wachtel, M. F. (1980). Mass production of Bacillus penetrans for the biological control of root-knot nematodes. Nematologica 26, 308-312. doi: 10.1163/187529280X00260

Stirling, G. R., and White, A. M. (1982). Distribution of a parasite of root-knot nematodes in South Australian vineyards. Plant Dis. 66, 52-53.

Stirling, G. R., Wong, E., and Bhuiyan, S. (2017). Pasteuria, a bacterial parasite of plant-parasitic nematodes: its occurrence in Australian sugarcane soils and its role as a biological control agent in naturally infested soil. Australas. Plant Pathol. 46, 563-569. doi: 10.1007/s13313-017-0522-z

Sun, M. H., and Liu, X. Z. (2000). Suppressive soils of soybean cyst nematode in China. Acta Phytopathol. Sin. 30, 353-356.

Szabó, M., Csepregi, K., Gálber, M., Virányi, F., and Fekete, C. (2012). Control plant-parasitic nematodes with Trichoderma species and nematode-trapping fungi: The role of chi18-5 and chi18-12 genes in nematode egg-parasitism. Biol. Control 63, 121-128. doi: 10.1016/j.biocontrol.2012.06.013

Taylor, C. E., and Brown, D. J. F. (1997). Nematode Vectors of Plant Viruses. Wallingford, CT: CAB International.

Tian, B., Yang, J., and Zhang, K.-Q. (2007). Bacteria used in the biological control of plant-parasitic nematodes: populations, mechanisms of action, and future prospects. FEMS Microbiol. Ecol. 61, 197-213. doi: 10.1111/j.1574-6941.2007. 00349.x

Topalović, O., Bredenbruch, S., Schleker, A. S. S., and Heuer, H. (2020a). Microbes attaching to endoparasitic phytonematodes in soil trigger plant defence upon root penetration by the nematode. Front. Plant Sci. 11:138. doi: 10.3389/fpls. 2020.00138

Topalović, O., Elhady, A., Hallmann, H., Richert-Pöggeler, K., and Heuer, H. (2019). Bacteria isolated from the cuticle of plant-parasitic nematodes attached to and antagonized the root-knot nematode Meloidogyne hapla. Sci. Rep. 9:1477. doi: 10.1038/s41598-019-47942-7

Topalović, O., and Heuer, H. (2019). Plant-nematode interactions assisted by microbes in the rhizosphere. Curr. Issues Mol. Biol. 30, 75-88. doi: 10.21775/ cimb.030.075

Topalović, O., Heuer, H., Reineke, A., Zinkernagel, J., and Hallmann, J. (2020b). Antagonistic role of the microbiome from a Meloidogyne hapla-suppressive soil against phytonematode species with different life strategies. Nematology 22, 75-86. doi: 10.1163/15685411-00003285

Vachon, V., Laprade, R., and Schwartz, J.-L. (2012). Current models of the mode of action of Bacillus thuringiensis insecticidal crystal proteins: a critical review. J. Invertebr. Pathol. 111, 1-12. doi: 10.1016/j.jip.2012.05.001

van der Putten, W. H., Bradford, M. A., Pernilla Brinkman, E., van de Voorde, T. F. J., and Veen, G. F. (2016). Where, when and how plant-soil feedback matters in a changing world. Funct. Ecol. 30, 1109-1121. doi: 10.1111/13652435.12657

Wang, N., Zhang, Y., Hussain, M., Li, K., Xiang, M., and Liu, X. (2016a). The mitochondrial genome of the nematode endoparasitic fungus Hirsutella rhossiliensis. Mitochondrial DNA B 1, 114-115. doi: 10.1080/23802359.2016. 1143336

Wang, N., Zhang, Y., Jiang, X., Shu, C., Hamid, M. I., Hussain, M., et al. (2016b). Population genetics of Hirsutella rhossiliensis, a dominant parasite of cyst nematode juveniles on a continental scale. Appl. Environ. Microbiol. 82, 6317-6325. doi: 10.1128/AEM.01708-16

Wei, J.-Z., Hale, K., Carta, L., Platzer, E., Wong, C., Fang, S.-C., et al. (2003). Bacillus thuringiensis crystal proteins that target nematodes. Proc. Natl. Acad. Sci. U.S.A. 100, 2760-2765. doi: 10.1073/pnas.0538072100

Weibelzahl-Fulton, E., Dickson, D. W., and Whitty, E. B. (1996). Suppression of Meloidogyne incognita and M. javanica by Pasteuria penetrans in field soil. J. Nematol. 28, 43-49.

Weller, D. M., Raaijmakers, J. M., Gardener, B. B., and Thomashow, L. S. (2002). Microbial populations responsible for specific soil suppressiveness to plant pathogens. Annu. Rev. Phytopathol. 40, 309-348. doi: 10.1146/annurev.phyto. 40.030402.110010

Westcott, S. W., and Kluepfel, D. A. (1993). Inhibition of Criconemella xenoplax egg hatch by Pseudomonas aureofaciens. Phytopathology 83, 1245-1249.

Westphal, A., and Becker, J. O. (1999). Biological suppression and natural population decline of Heterodera schachtii in a California field. Phytopathology 89, 434-440. doi: 10.1094/PHYTO.1999.89.5.434

Westphal, A., and Becker, J. O. (2000). Transfer of biological soil suppressiveness against Heterodera schachtii. Phytopathology 90, 401-406. doi: 10.1094/PHYTO. 2000.90.4.401

Westphal, A., and Becker, J. O. (2001). Components of soil suppressiveness against Heterodera schachtii. Soil Biol. Biochem. 33, 9-16. doi: 10.1016/S0038-0717(00) 00108-5

Williams, T. D. (1969). The effects of formalin, nabam, irrigation and nitrogen on Heterodera avenae Woll., Ophiobolus graminis Sacc. and the growth of spring wheat. Ann. Appl. Biol. 64, 325-334. doi: 10.1111/j.1744-7348.1969.tb02882.x

Williamson, V. M., and Hussey, R. S. (1996). Nematode pathogenesis and resistance in plants. Plant Cell 8, 1735-1745. doi: 10.1105/tpc.8.10.1735

Wilschut, R. A., van der Putten, W. H., Garbeva, P., Harkes, P., Konings, W., Kulkarni, P., et al. (2019). Root traits and belowground herbivores relate to plant-soil feedback variation among congeners. Nat. Commun. 10:1564. doi: 10.1038/s41467-019-09615-X

Xu, Y.-Y., Lu, H., Wang, X., Zhang, K.-Q., and Li, G.-H. (2015). Effect of volatile organic compounds from bacteria on nematodes. Chem. Biodivers. 12, 14151421. doi: $10.1002 / \mathrm{cbdv} .201400342$

Yang, L.-L., Huang, Y., Liu, J., Ma, L., Mo, M.-H., and Li, W.-J. (2012). Lysinibacillus mangiferahumi sp. nov., a new bacterium producing nematicidal volatiles. Antonie van Leeuwenhoek 102, 53-59. doi: 10.1007/s10482-012-9712-4 
Yang, Y., Yang, E., An, Z., and Liu, X. (2007). Evolution of nematode-trapping cells of predatory fungi of the Orbiliaceae based on evidence from rRNA-encoding DNA and multiprotein sequences. Proc. Natl. Acad. Sci. U.S.A. 104, 8379-8384. doi: 10.1073/pnas.0702770104

Yin, B., Valinsky, L., Gao, X., Becker, J. O., and Borneman, J. (2003a). Identification of fungal rDNA associated with soil suppressiveness against Heterodera schachtii using oligonucleotide fingerprinting of ribosomal RNA genes. Phytopathology 93, 1006-1013. doi: 10.1094/PHYTO.2003.93.8.1006

Yin, B., Valinsky, L., Gao, X. B., Becker, J. O., and Borneman, J. (2003b). Bacterial rRNA genes associated with soil suppressiveness against the plant-parasitic nematode Heterodera schachtii. Appl. Environ. Microbiol. 69, 1573-1580. doi: 10.1128/AEM.69.3.1573-1580.2003

Yu, Q., and Coosemans, J. (1998). Fungi associated with cysts of Globodera rostochiensis, G. pallida, and Heterodera schachtii, and egg masses and females of Meloidogyne hapla in Belgium. Phytoprotection 79, 63-69. doi: 10.7202/ 706135ar

Zhang, W., Hu, C., Hussain, M., Chen, J., Xiang, M., and Liu, X. (2019). Role of low-affinity calcium system member Fig1 homologous proteins in conidiation and trap-formation of nematode-trapping fungus Arthrobotrys oligospora. Sci. Rep. 9:4440. doi: 10.1038/s41598-019-40493-x
Zhou, D., Feng, H., Schuelke, T., De Santiago, A., Zhang, Q., Zhang, J., et al. (2019). Rhizosphere microbiomes from root knot nematode non-infested plants suppress nematode infection. Microb. Ecol. 78, 470-481. doi: 10.1007/ s00248-019-01319-5

Zuckerman, B. M. (1983). Hypotheses and possibilities of intervention in nematode chemoresponses. J. Nematol. 15, 173-182.

Zuckerman, B. M., Dicklow, M. B., Coles, G. C., Garcia-E, R., and MarbanMendoza, N. (1989). Suppression of plant parasitic nematodes in the chinampa agricultural soils. J. Chem. Ecol. 15, 1947-1955. doi: 10.1007/BF01012278

Conflict of Interest: The authors declare that the research was conducted in the absence of any commercial or financial relationships that could be construed as a potential conflict of interest.

Copyright (c) 2020 Topalović, Hussain and Heuer. This is an open-access article distributed under the terms of the Creative Commons Attribution License (CC BY). The use, distribution or reproduction in other forums is permitted, provided the original author(s) and the copyright owner(s) are credited and that the original publication in this journal is cited, in accordance with accepted academic practice. No use, distribution or reproduction is permitted which does not comply with these terms. 